\title{
Polydiscursive Consensus in the Dialogue of Tradition and Modernity
}

\author{
Andrey Mishuchkov \\ Department of Scientific Research \\ Orenburg Theological Seminary of the Orenburg \\ Diocese of the Russian Orthodox Church 17 \\ Orenburg, Russia \\ unitatem@mail.ru
}

\author{
Sergei Nizhnikov \\ Department of the History of Philosophy \\ Peoples' Friendship University of Russia \\ Moscow, Russia \\ nizhnikovs@mail.ru
}

\begin{abstract}
This article is devoted to understanding the problems of interaction between the discourses of traditionalist and modernist societies, and the possibility of achieving a dialogical consensus in intercivilizational communication. A polydiscursive consensus in the dialogue of cultures creates a new cross-cultural communication event, based on the duality of inclusive and exclusive types of rationality. The principle of equivocative discursiveness is laid on the basis of universal civilizational ethics and intercivilizational interaction. From an analysis of the types of social communication of $\mathrm{Yu}$, Habermas and M. Weber, a typology of discourses participating in the dialogue of cultures of traditionalist and modernist society from the aspect of the concept of post-secularism is proposed. The principles of universal civilizational ethics underlie the dialogical project of a multipolar world of civilizations as a safe strategy for the development of mankind.
\end{abstract}

Keywords-traditionalism; modernity; intercivilizational communication; polydiscursive consensus; dialogue philosophy; typology of discourses; equivocative discourse; civilizational ethics of dialogue

\section{INTRODUCTION}

The modern field of communications is permeated with the internal conflict between traditional culture and the technocratic world of values, which claims to break with the past cultural tradition. Traditionalism and modernity are two key characteristics of intercivilizational communication, which determines the strategies for the future development of mankind.

Western civilization thinks of its communicative position in terms of progressivism and relativism represents a break with traditional culture. Non-Western civilizations (in particular, India, China, Russia, Islamic, and African civilizations) are working to combine modernization (modern design) and traditionalism.

The concept of modernity is based on dissatisfaction with

Disclosure: This publication was supported by the Ministry of Education and Science of the Russian federation (Agreement number 02.A03.21.0008) for Peoples' Friendship University of Russia (RUDN University). This article also was financially supported within the framework of the scientific project № 17-11-56002a(p) by the Russian Humanitarian Scientific Foundation and the Government of the Orenburg Region. oneself, a break with the former identity, the relativity of cultural identities, the modernization of social institutions and the whole system of social relations, and the transformation of man as a subject of social change. The content of traditionalism is the peculiarity of national cultural self-awareness as the completeness of culture in itself, selfsufficiency and the absoluteness of cultural values, the priority of the value of the past as an algorithm for the future.

Modern humanity is a dialectical unity of the traditional (family, church, nationality) and modernist institutions (economics, politics, technology, the Internet, contemporary culture). In the communicative space of civilizations, a complex system is formed by various institutional and noninstitutional discourses of traditional and modern society. There is the effect of polydiscursivity in intercultural communication, a synchronous representation of the discourse system in the communicative position of countries, cultures, and personalities. A new quality of cross-cultural events arises - both intrapersonal and interpersonal civilizational communication, which includes various, often opposite, cognitive-value worlds. The principle of effectiveness of such cross-cultural communication is the multidiscussive consensus of its participants, based on the recognition of: the legitimacy of many discourses in communication; a moral consensus on the general polydiscursive ethics of dialogue; and civil-law consensus on the recognition of the system of rights and freedoms of individuals and public institutions. As a recognition of the equivalence in the civilizational communication of the multiple discourses of traditionalism and modernism, polydiscursive pluralism is the development of the principle of polydiscursive civilizational consensus. It creates a new format of international communication based on the rejection of the unipolarity of the civilizational development of mankind, the recognition of the principle of a multipolar world, the recognition of the presumption of cultural and civilizational diversity, the recognition of the dynamic and interconnectedness of the exclusive-inclusive world of civilizations, the recognition of the fundamental humanitarian crisis within modern civilization, and the reformatting of the system of international relations and the institutions that emerged in the era of confrontations between blocs of countries in the past century. The humanitarian 
future of mankind which preserves its cultural diversity largely depends on the realization of this multipolar form of inter-civilizational dialogue.

\section{RATIONALE FOR TYPES OF SOCIAL ACTION}

An urgent task arises for the philosophy of dialogue to find a form of cultural compromise and communication between the two worlds (traditional and modernity) for preserving the stability of civilizations and overcoming the civilizational contradiction. Jurgen Habermas, the representative of the European philosophy of dialogue, created the "theory of communicative behavior" in modern society from the aspect of analyzing two levels: the "system", as in the material world and the sphere of institutions (market, bureaucracy), and the "life world", as a symbolic subjective world of the person's identity. The communicative rationality corresponds to the living world; the instrumental rationality to the system world. These two types of rationality form the strategies of discursive positions - traditionalism (the priority of the spiritual life world over the material values of the "system") and modernity (the priority of the material over the spiritual). The main problem and specificity of the present, according to Yu. Habermas, is the separation of the "system" and the "life world", expressed in the process of breaking modernity from tradition. Modernity is associated with freedom from the dictates of traditions and the paternalism of power, with freedom of judgment, choice and personal responsibility, with the dynamism of social processes, and with the dominance of instrumental rationality. Communicative rationality serves to strengthen the traditions in society, social interactions, the formation of cultural solidarity and identity of the individual, and the dialogical overcoming of the rupture of tradition and modernity in the cultural mentality of mankind.

Yu. Habermas defines the key concept of his philosophy of "communicative action", as a "circular process in which the position of the actor is twofold: he is the initiator of actions, calculating which of them can master this or that situation; and at the same time the product of the traditions in which he lives, the cohesive groups to which he belongs, and the processes of socialization in which he attains maturity" [2]. Communicative action as a socially-mediated interaction, social perception, or a form of information exchange, is based on symbolic acts through which subjects accept and understand communicative messages, and also control actions through appropriate communication forms (negotiations, consensus).

Using the concepts of M. Weber (social action) and J.L. Austin (speech acts), Yu. Habermas identifies the types of human behavior: Communicative type in the linguistic sphere, using language with the aim of achieving mutual understanding in the horizon of the vital world for actors of communication; Strategic type in the political and economic sphere, pursuing utilitarian interests and based on manipulative behavior on the basis of incentives for reward and punishment; Instrumental type in the technosphere and economics (like M. Weber's goal-oriented behavior); Normregulating type in the field of law, where the norms express the universally recognized interests and values of society, which are followed by all its members (similar to the valuerational behavior of M. Weber); and Expressive type for the formation of the image (self-presentation) of a person, promoting free expression by the subject of his individuality. This type includes the affective behavior of a person, according to $\mathrm{M}$. Weber, significantly expanding its content. Thus, Yu. Habermas shows that socially there is a significant number of strategies for human behavior, which affects the sphere of communication. The fundamental difference of communicative action from all other types of social action is the realization of mechanisms of mutual understanding between people, and not the achievement of pragmatic success, benefit, or interests. Mutual understanding is not a goal that is imposed manipulatively, but as a value, which is eagerly pursued by all communication subjects who seek in the value consensus the foundation of social solidarity and the stability of society. Such a humanistic dimension of communicative action reveals it as a type of value-rational behavior, favorably distinguishing it from strategic behavior that has a pragmatic content.

According to M. Weber, at the heart of the project of modernity is a goal-oriented type of social action, generated by instrumental rationality. Value-based action strengthens traditional culture, emphasizing the self-sufficient value of a particular behavior as such, no matter what it leads to. Classification of types of social action by M. Weber is based on a decrease in the degree of rationality of individuals' behavior: goal-oriented, value-rational, traditional, and affective. The last two types of action are on the border of meaningful rational behavior.

According to M. Weber, the lowest type of social action is called a psychologically-stereotyped behavior based on a "long habit", a reactive imitation, which, together with the affective type, is irrationally subjective in its content. In this case, the term "traditional" is used purely in the narrow sense, in the content plan as a cultural-psychological inertia of thinking. As M. Weber himself notes, the traditional action is "an automatic reaction to the usual irritation in the direction of the once assimilated installation" [3]. Being ideologically related to the past of the "tradition", which is opposed to modernity (capitalism, rationality, and enlightenment), Weber thus intentionally narrows this concept. In every society, a type of integrity of public practice has developed, including all four types of social action. Also, each person has his own individual form of integrity of expression of these types with a dominant of each type in this or that situation. The ideological clash occurs between two types of ideological strategies - the project of modernity and traditionalism. As noted by M. Weber, "The first enemy, who had to face the" spirit "of capitalism and who had a certain lifestyle, normatively conditioned and acting in an" ethical "guise, was the type of perception and behavior that can be called traditionalism" [4]. One of the ideas of his work is to clarify the role of the Protestant tradition of ethics in the spirit of capitalism. In fact, M. Weber revealed the socio-historical contradiction between traditionalism and modernity. Disclosure on the modern material of this contradiction in the context of the conflict of traditional values and globalization is presented in the monograph by $\mathrm{A}$. 
Mishuchkov [5]. He reveals the specifics of the polydiscursiveness and institutionalization of the modern process of the dialogue of civilizations.

Yu. Habermas proposes a project of global intercultural discourse based on the concepts of discursive ethics and rationality, which help to find mutual understanding between religious and secular mentalities, forming different cultural "modernities". Within the framework of the philosophical concept of post-secularism, a joint collection by $\mathrm{Yu}$. Habermas and Pope Benedict XVI (Ratzinger) was created [6]. In this discussion, the parties agreed on a general statement of the destruction of civic solidarity as the foundation of a democratic state, and on the problem of a universal human ethos reconciling secular and religious discourse. Hence is born the search for a consensus of secular and religious ethics based on the reconciliation of faith and reason in discursive ethics. Yu. Habermas argues that "our modern society must develop a new post-secular sensitivity and rely on religion as a source of public discourse, cure the pathologies of modernization and the falsity of secularization, including preventing a crisis of the individualistic system of relations that prevents the creation of real and strong communities in an inclusive society" [7]. The concepts of post-secularism, the types of social action of $\mathrm{Yu}$. Habermas, allowed putting forward a system typology of the inclusive-exclusive discourses participating in intercivilizational universal communication.

\section{TYPOLOGY OF DISCURSES OF DIALOGUE}

Proceeding from the classifications presented by $\mathrm{Yu}$.Habermas and M. Weber, it is now possible to formulate the following scheme of types of social communication.

TABLE I. SCHEME OF TYPES OF SOCIAL COMMUNICATION (DisCOURSES)

\begin{tabular}{|c|c|c|c|c|}
\hline Type of society & \multicolumn{2}{|c|}{ Traditional society } & \multicolumn{2}{|c|}{ Post-traditional modern society } \\
\hline Type of morality & \multicolumn{2}{|c|}{$\begin{array}{l}\text { Conventional heteronomous collectivist } \\
\text { morality }\end{array}$} & \multicolumn{2}{|c|}{ Post-conventional autonomous individualistic morality } \\
\hline Type of values & \multicolumn{2}{|c|}{$\begin{array}{l}\text { Traditional values with the priority of human } \\
\text { responsibilities and the orientation towards the } \\
\text { collective good }\end{array}$} & \multicolumn{2}{|c|}{$\begin{array}{l}\text { Instrumental values with the priority of human rights } \\
\text { and orientation towards individual benefits }\end{array}$} \\
\hline $\begin{array}{l}\text { Level of communication } \\
\text { organization }\end{array}$ & Institutional & Non-institutional & Institutional & Non-institutional \\
\hline Type of social action: & \multicolumn{2}{|l|}{ Traditionalist } & \multicolumn{2}{|l|}{ Innovative } \\
\hline 1. Communicative & Religious discourse & $\begin{array}{l}\text { Household } \\
\text { discourse }\end{array}$ & Scientific, teaching discourses & Personal discourse \\
\hline 2.Strategic Economic & $\begin{array}{l}\text { Economic and } \\
\text { politically-conservative } \\
\text { discourses }\end{array}$ & $\begin{array}{l}\text { Business } \\
\text { communications }\end{array}$ & $\begin{array}{l}\text { Economic and political } \\
\text { progressive discourses }\end{array}$ & $\begin{array}{l}\text { Innovative business } \\
\text { communications, } \\
\text { expert discourse }\end{array}$ \\
\hline 3. Instrumental & Handicraft discourse & Handicraft general & Technical advisory discourse & Virtual discourse \\
\hline 4. Normative & $\begin{array}{l}\text { Custom, discourse of } \\
\text { Judicators }\end{array}$ & Penal discourse & $\begin{array}{l}\text { Legal } \\
\text { discourse }\end{array}$ & Norm-creation \\
\hline 5. Expressive-affective (dramatic) & Mythological discourse & $\begin{array}{l}\text { Discourse } \\
\text { collective } \\
\text { manifestation }\end{array}$ & $\begin{array}{l}\text { Art-discourses, advertising } \\
\text { discourse of personal } \\
\text { manifestation }\end{array}$ & Art - Creation \\
\hline 6. Stereotype-psychological & Ritualism & Imitation & Psychological discourse & Game communication \\
\hline
\end{tabular}

Traditional society involves limiting the internal freedom of man through collective norms of conduct. In a posttraditional society, a person seeks to limit external institutional constraints, developing personality-oriented behavior. The conventional heteronomous collectivist morality of a traditional society is based on the priority of the collective good, the social inviolability (absoluteness) of morality and sanctions, and moral orthodoxy. Postconventional autonomous individualistic morality in a posttraditional society is based on the priority of human rights, an orientation toward the individual good of the individual, and moral relativism. The levels of organization of communication in each type of society are divided into institutional and non-institutional. Institutional communication organizes the discursive interaction of people realizing their status-role opportunities within the framework of historically developed social institutions. Noninstitutional communication arises in a situation where people interact, not as representatives of social institutions, not under the influence of power, but in powerless (symmetrical) relations, as culturally equal individuals with a highly developed inner world.
In this table, only the possible options for the completion of examples of various discursive practices in sections of various types of social action are presented schematically.

Communicative type of social action implies mutual understanding of the parties of communication is the key in intercivilizational communication. Traditionally-religious discourse presupposes the inclusion of ecclesiastical authority and the church affiliation of the parties to communication, the unchanging religious and ethical truths. In non-institutional communication, religious discourse is reduced to the dominant ethical themes, which are of a soteriological nature. A vivid example of non-institutional communication is the everyday discourse about the themes of daily life. In the institutional-innovative level of discourses, scientific discourse dominates, presupposing a constant generation of new knowledge and its organization, and the institutional practice of implementation. If the religious and pedagogical discourse is aimed at forming an unchanging picture of the world by the parties of communication, the scientific and pedagogical discourse includes a constant update of the world picture and its dynamics. Unlike everyday discourse, personal discourse is 
aimed at breaking through in interpersonal relationships, finding new cultural meanings in philosophical and literary discourses, and widening the horizons of being personalities.

The strategic type of traditional social action is aimed at maintaining and preserving the economic, social and political structure of society; the innovative type of action is aimed at modernizing society. Accordingly, conservative and progressive discourses compete in the society. Noninstitutional business communication, in its turn, also differs from traditional (culture of personal communication) and innovative (expert discourse), when new links and business strategies are formed.

The instrumental type of social action is presented, first of all, in the technical sphere and presupposes an orientation toward observing the behavior of other people, using anticipation of such behavior as a means of constructing one's own actions. In traditional society, craft discourse and practice are called upon to develop a qualified master of his craft, who then creates a masterpiece (a unique product). Handicraft communication creates extra-institutional settings for the formation of such a technical culture specialist. Modern technical and administrative discourses form the person of Art Nouveau type, creating a new product with unusual properties (masterpiece-innovation). Virtual discourse is formed on the Internet as in an intellectual community that has not a vertical organization, but a horizontal network organization. Due to the development of technical means and the complexity of the organization of knowledge on the Internet, virtual discourse is innovative in nature and rapidly institutionalized in the field of mass communication.

The normative type of social action serves the sphere of morality and law in society. In a traditional society, it is a heteronomous morality and law based on customs; in a posttraditional society, there is an individualization and relativization of morality, and then emphasis on rights. Instead of conventional collectivist morality, the postconventional autonomous morality begins to dominate. In the institutional field of discourses of traditional society, everything ultimately legitimizes law as a sacred and unchanging institution of society. In everyday noninstitutional communication, it operates by the principle "an eye for an eye and a tooth for a tooth" (retaliation). In modern society, the morality of non-institutional communication tends to realize the paradox of good (to overcome evil with good), as the more appropriate civilizational strategy for the development of society. The legal discourse of a post-traditional legal society forms a civil legal consciousness of a spiritually independent person who consciously and freely accepts the system of the society's right that protects the rights and freedoms of the individual. Following institutional norm-setting, noninstitutional rule-making develops in the communication processes as an expression and deepening of the inner moral and legal culture of the individual.

The expressive-affective type of social action at the level of traditional society is represented by mythological discourse as a special illusory holistic verbal and cogitative practice that operates emotional-value syncretic representations (images) of social interactions of the individual at the sensually-pre-reflective level of world development. Myth is a universal form of institutionalization of culture and communication in mankind. In this sense, it organically enters the polydiscursive communicative culture of the individual and society. Carnival culture in traditional society is a vivid example of non-institutional discourse of collective manifestation of the person, where anonymity and a change of roles equalize its participants. In modern society discourses of personal manifestation prevail (art discourses), where a person creates many images of himself in various interpersonal relationships. Moreover, the discourses set the boundaries of the manifestation of the individual, transferring it from external compulsion to internal selfcoercion, to revealing the creative potentials of personal presentation.

The stereotyped-psychological type of social action rests on the discursive principles of institutional ritualism and non-institutional imitation in traditional society. With the development of reflexive psychological discursiveness in modern society, a person reproduces more complex psychological neoplasms in interpersonal communication associated with the self-construction of the personality in the paradigm of external civil and internal spiritual freedom [8]. The non-institutional aspect of this type of social action in modern society is represented in the game discourse, liberating a person from the burden of ordinary life, the inevitability of social obligations, and in the manifestation of the personality in a new form.

The discourses listed in the table are only a small part of the many existing discourses in society, and the boundaries of their separation in terms of institutionality and noninstitutionality are completely arbitrary. The heuristic power of this scheme of discourses is in understanding the fundamental fact of the systemic nature of the discursive field of communication in society, and the dialectical and genetic unity of the discourses of traditional and modern society. This scheme of types of social action more precisely details the system of civilizational communication that arises both inside and outside between civilizations.

\section{CONCLUSION}

Therefore, it is possible to draw following conclusions from the above arguments:

- A whole set of historically formed types of rationalities in world culture is represented in civilizational communication: cognitive-instrumental rationality of science, economic market rationality, aesthetically expressive rationality of art, theological rationality of religion, and political, legal, and moral types of rationality.

- Proceeding from this historical fact of the inner explicitness of exclusive traditional discourses and inclusive post-traditional discourses, a communicative axiom follows: the principle of polydiscursive consensus and pluralism. It sets the 
cross-cultural humane dimension of civilizational communications that have the equivocal (ambiguous, exclusive-inclusive) nature of social relations.

- The priority in achieving a civilizational consensus in communication lies in the equivocation (duality) of discursive ethics (which includes religious and secular morals) as the basis of civilizational identity and communication. It is this two-sided, secularreligious civilizational design of discursive ethics that makes it possible to discover the potential of the true universality of intercivilizational relations and to develop an effective strategy for the safe future of mankind. Equivocal discourse will allow the dialogue of civilizations to realize the unity of secular and religious potentials of various cultural concepts in the polar dialectical harmony of universal civilizational ethics.

- This will allow the development of an international model of an ideal communicative situation in which the mechanisms of implementing various types of social action, both in traditional society and in a posttraditional society, would be compatible. The very fate of the dialogue project of civilizations, the solution of the global problems of mankind, and, ultimately, the humane future of humanity as a whole, depend on finding such a complimentary communicative polydiscursive consensus.

\section{REFERENCES}

[1] Yu. Habermas, Moral Consciousness and Communicative Action, SPb. : Nauka, 2000. P. 202.

[2] M. Weber, Basic sociological concepts. // Weber M. Selected works, Moscow: Progress, 1990. R. 628.

[3] M. Weber, Protestant Ethics and the Spirit of Capitalism // Weber M. Selected Pro-Media, M.: Progress, 1990. - P. 80.

[4] A.A. Mishuchkov, Dialogue of Civilizations: Traditional Values in Conditions of Globalization (monograph). - Orenburg: PKI University LLC, 2017.

[5] J. Habermas, J. Ratzinger (Benedict XVI), The Dialectics of Secularization. About reason and religion. M.: Biblical and Theological Institute of St. The Apostle Andrew, 2006.

[6] Intervento di apertura al Seminario "Promoting Religious Freedom and Peaceful Co-existence. (Roma, 11 febbraio 2013). [Electronic resource].

URL: http://www.ambalgeri.esteri.it/NR/rdonlyres/05CB85F3-84D0-4AA4AD50-E21BE83DA26F/0/InterventoaperturaSigMinistro.pdf

[7] S.A. Nizhnikov, The spiritual problem in Western and Eastern culture and philosophy. Monograph. - Moscow: INFRA-M, 2012. P. 133. 